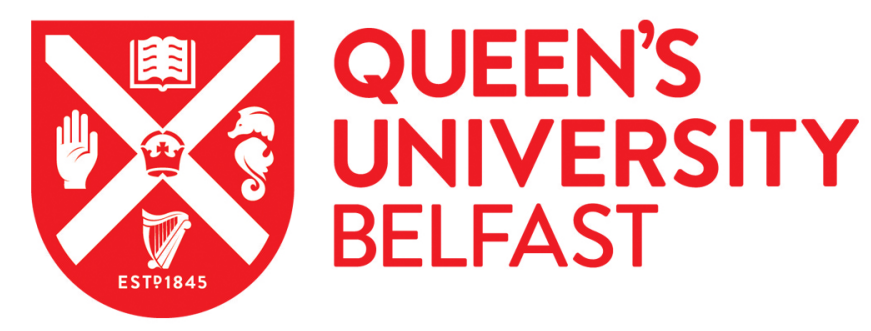

\title{
Notched response of non-crimp fabric thin-ply laminates: Analysis methods
}

Arteiro, A., Catalanotti, G., Xavier, J., \& Camanho, P. P. (2013). Notched response of non-crimp fabric thin-ply laminates: Analysis methods. Composites Science and Technology, 88, 165-171.

https://doi.org/10.1016/j.compscitech.2013.09.003

\section{Published in:}

Composites Science and Technology

\section{Document Version:}

Peer reviewed version

\section{Queen's University Belfast - Research Portal:}

Link to publication record in Queen's University Belfast Research Portal

\section{Publisher rights}

Copyright 2013 Elsevier.

This manuscript is distributed under a Creative Commons Attribution-NonCommercial-NoDerivs License

(https://creativecommons.org/licenses/by-nc-nd/4.0/), which permits distribution and reproduction for non-commercial purposes, provided the author and source are cited.

\section{General rights}

Copyright for the publications made accessible via the Queen's University Belfast Research Portal is retained by the author(s) and / or other copyright owners and it is a condition of accessing these publications that users recognise and abide by the legal requirements associated with these rights.

Take down policy

The Research Portal is Queen's institutional repository that provides access to Queen's research output. Every effort has been made to ensure that content in the Research Portal does not infringe any person's rights, or applicable UK laws. If you discover content in the Research Portal that you believe breaches copyright or violates any law, please contact openaccess@qub.ac.uk. 


\title{
Notched response of non-crimp fabric thin-ply laminates: analysis methods
}

\author{
A. Arteiro ${ }^{\mathrm{a}}$, G. Catalanotti ${ }^{\mathrm{a}}$, J. Xavier ${ }^{\mathrm{b}}$, P.P. Camanho ${ }^{\mathrm{a}, *}$ \\ ${ }^{a}$ DEMec, Faculdade de Engenharia, Universidade do Porto, Rua Dr. Roberto Frias, 4200-465 Porto, Portugal \\ ${ }^{b}$ CITAB, Universidade de Trás-os-Montes e Alto Douro, Engenharias I, Apartado 1013, 5001-801 Vila Real, Portugal
}

\begin{abstract}
Analysis methods to predict the open-hole tensile and compressive response of thin-ply non-crimp fabric laminates are investigated in this paper. The point- and average-stress models and the Finite Fracture Mechanics model are used. It is shown that all models predict with reasonable accuracy the observed size effects in both tension and compression. The Finite Fracture Mechanics model, which requires two material properties (the unnotched strength and the fracture toughness) and does not need calibration from a baseline specimen, is used to predict the notched response of thin-ply non-crimp fabric laminates and of typical aerospace grade laminates based on unidirectional preimpregnated plies. No substantial differences in notch sensitivity and inherent material/geometry brittleness is predicted.
\end{abstract}

Keywords:

A. Laminate, B. Fracture, C. Stress concentrations.

\section{Introduction}

Tow-spread thin-ply laminates are a new class of composite materials with particular interest for the aircraft industry. These laminates are based on flat and straight plies with dry ply thicknesses as low as $0.02 \mathrm{~mm}$, obtained by continuously and stably opening fiber tows in a pneumatic device.

Thin-ply laminates have several advantages with respect to traditional laminates. In a previous work [1], an extensive experimental test program was conducted to investigate the mechanical response of thin-ply laminates, including notched strength, size effects, brittleness, and bearing strength. It was concluded that the spread tow thin-ply technology is able to produce laminates

\footnotetext{
*Corresponding author

Email address: pcamanho@fe.up.pt (P.P. Camanho)
} 
whose application in primary structures may result in some structural integrity improvements, without degradation of the notched response of the composite structures, including (i) delay of subcritical damage such as delamination and transverse cracking, which is particularly important in applications subjected to mechanical fatigue and load reversals, and (ii) optimized behavior in mechanically fastened joints, due to the superior performance of these laminates when subjected to bearing loads. However, in order to accurately predict the notched response of these laminates, a study on the applicability of existing analysis methods should be performed.

The first objective of this paper is to assess the validity of current analytical tools in predicting the notched response of thin-ply laminates. The results obtained in the experimental test program discussed in a previous paper [1] are compared with the predictions of the traditional point-stress (PS) and average-stress (AS) models [2], and of the newly developed Finite Fracture Mechanics (FFMs) model [3]. The second objective is to complement the previous experimental work [1], using the FFMs model to evaluate size effects, notch sensitivity and brittleness of carbon fiber reinforced polymer (CFRP) composites. Adequate trends, predicted for the same conditions and geometries, are used to compare the notched response of non-crimp fabric (NCF) thin-ply laminates and typical aerospace grade CFRP laminates, for which experimental data is only available for a limited range of geometries.

\section{Strength prediction model}

The model recently proposed by Camanho et al. [3], which is based on the concept of Finite Fracture Mechanics (FFMs) originally developed by Leguillon [4] and Cornetti et al. [5], results in improvements over the traditional strength prediction methods (see refs. $[3,6,7]$ for comparisons). The FFMs model assumes that crack propagation occurs when a stress-based criterion, similar to Whitney and Nuismer's AS model [2], and an energy-based criterion are simultaneously satisfied, and considers that failure occurs by the propagation of kinematically admissible cracks with finite sizes. The strength predictions using the FFMs model can be obtained in a few seconds, without the need to use finite element analysis (FEA) or complex computational methods, using only independently measured material properties: the laminate unnotched strength $\left(X^{L}\right)$ and fracture toughness $\left(\mathcal{K}_{I c}\right)$ $[3]$.

Since there are no standard test methods to measure the laminate fracture toughness, Camanho 
et al. [3] propose the use of the FFMs analysis of the specimens with a central crack, as shown in figure 1. These specimens are particularly suitable due to the simplicity of the geometry and data reduction method. Following this approach, the tensile and compressive remote stresses at failure, obtained in center-notched tension and compression tests, respectively, and the tensile and compressive unnotched strengths measured in the experimental program [1] are used for the calculation of the tensile and compressive fracture toughness of the laminates. However, unlike Camanho et al. [3], who used the stress distribution and the stress intensity factor solution for an infinite plate, finitewidth corrected solutions are used here. In addition, since cracks in laminated plates are similar to elliptical openings with high aspect ratios, which more closely resemble the elliptical notch than the theoretical crack (which has zero notch tip radius that cannot be obtained experimentally) [8], the stress distribution for a central elliptical notch is used to solve the FFMs stress-based criterion. Also, by using the stress distribution for a central elliptical notch, the stress singularity at the crack tip is avoided and a finite stress concentration is considered, which more closely approximates the real problem.

According to the FFMs model [3], failure in a specimen with a central crack (figure 1) occurs when the following system os equations is satisfied:

$$
\left\{\begin{array}{l}
\frac{1}{l} \int_{a}^{a+l} \sigma_{y y}(x, 0) \mathrm{d} x=X^{L} \\
\frac{1}{l} \int_{a}^{a+l} \mathcal{K}_{I}^{2}(a) \mathrm{d} a=\mathcal{K}_{I c}^{2}
\end{array}\right.
$$

where $\sigma_{y y}(x, 0)$ is the stress distribution along the $x$-axis, $\mathcal{K}_{I}(a)$ is the stress intensity factor (SIF), and $l$ is the crack extension at failure.

Assuming that the normal stress profile for a finite plate is identical to that for an infinite plate except for a finite-width correction (FWC) factor, the stress distribution along the $x$-axis, $\sigma_{y y}(x, 0)$, is given as [8]:

$$
\sigma_{y y}(x, 0)=\frac{K_{T}}{K_{T}^{\infty}} \sigma_{y y}^{\infty}(x, 0)
$$

where $K_{T}^{\infty}$ and $K_{T}$ are, respectively, the stress concentration factors at the edge on the axis normal to the applied load of the central notch of an infinite orthotropic plate and a finite orthotropic plate, 
and $\sigma_{y y}^{\infty}(x, 0)$ is the stress distribution along the $x$-axis of an infinite orthotropic plate containing a central notch. Approximating the central notch by an elliptical opening of major semi-axis $a$ and minor semi-axis $b, K_{T}^{\infty}, K_{T}$ and $\sigma_{y y}^{\infty}(x, 0) \operatorname{read}[8]$ :

$$
\begin{aligned}
& K_{T}^{\infty}=1+\frac{1}{\lambda} \sqrt{2\left(\sqrt{\frac{E_{y}}{E_{x}}}-\nu_{y x}\right)+\frac{E_{y}}{G_{x y}}} \\
& \frac{K_{T}^{\infty}}{K_{T}}=\frac{\lambda^{2}}{(1-\lambda)^{2}}+\frac{1-2 \lambda}{(1-\lambda)^{2}} \sqrt{1+\left(\lambda^{2}-1\right)(2 a / W)^{2}}- \\
&-\frac{\lambda^{2}}{(1-\lambda)^{2}} \frac{(2 a / W)^{2}}{\sqrt{1+\left(\lambda^{2}-1\right)(2 a / W)^{2}}+} \\
&+\frac{\lambda^{7}}{2}\left(\frac{2 a}{W}\right)^{6}\left(K_{T}^{\infty}-1-\frac{2}{\lambda}\right)\left\{\left[1+\left(\lambda^{2}-1\right)\left(\frac{2 a}{W}\right)^{2}\right]^{-\frac{5}{2}}-\right. \\
&-\left(\frac{2 a}{W}\right)^{2}\left[1+\left(\lambda^{2}-1\right)\left(\frac{2 a}{W}\right)^{2}\right]^{-\frac{7}{2}} \\
& \frac{\sigma_{y y}^{\infty}(x, 0)}{\sigma^{\infty}}= \frac{\lambda^{2}}{(1-\lambda)^{2}}+\frac{(1-2 \lambda) \gamma}{(1-\lambda)^{2} \sqrt{\gamma^{2}-1+\lambda^{2}}+\frac{(1-\lambda)\left(\gamma^{2}-1+\lambda^{2}\right)^{\frac{3}{2}}}{\left(\lambda^{2}\right.}} \\
&-\frac{\lambda^{7}}{2}\left(K_{T}^{\infty}-1-\frac{2}{\lambda}\right)\left[\frac{7 \lambda^{2} \gamma}{\left(\gamma^{2}-1+\lambda^{2}\right)^{\frac{7}{2}}} \frac{\left(\gamma^{2}-1+\lambda^{2}\right)^{\frac{9}{2}}}{\lambda}\right]
\end{aligned}
$$

where $\sigma^{\infty}$ is the remote applied stress, and the parameters $\lambda$ and $\gamma$ are defined as:

$$
\begin{gathered}
\lambda=\frac{b}{a} \\
\gamma=\frac{x}{a}
\end{gathered}
$$

For quasi-isotropic laminates, $K_{T}^{\infty}=1+2 / \lambda$, and equations (4) and (5) get considerably simplified. The stress profile around a central notch is the same for tension and compression, and the same solution will be used in the calculation of fracture toughnesses in both types of loading.

When approximating a central notch, such as the one shown in the specimen of figure 1 , by an elliptical opening, different approaches may be chosen to define the ellipse's minor semi-axis $b$. For example, Tan [8] simulated central cracks of length $2 a$ by an elliptical opening of major axis $2 a$ and 
constant aspect ratio $\lambda=50$. Alternatively, the central notch of length $2 a$ can be simulated by an elliptical opening of major axis $2 a$, with a minor axis $2 b$ equal to the notch height $h$ (or two times the radius of the milling cutter used to obtain the notch); another possibility is to define the ellipse's minor axis $2 b$ such that the ellipse's curvature in the major axis, $\left.\rho\right|_{\theta=0}$, is equal to the notch tip radius (or radius of the milling cutter).

Figure 2 shows a comparison of the stress distribution in the vicinity of the notch tip considering the different approaches to simulate the central notch by an elliptical opening. In addition, figure 2 also shows the stress distribution of a plate with a U-shaped central notch obtained from a finite element model developed using the commercial finite element package Abaqus 6.11-2; 0.05 mm long 4-node bilinear plane stress quadrilateral finite elements, with reduced integration and hourglass control (CPS4R), were used in the vicinity of the notch tip. By defining the ellipse's minor axis $2 b$ such that the ellipse's curvature in the major axis is equal to the notch tip radius gives the best approximation for the stress distribution along the $x$-axis in U-shaped notched plates, since the corresponding analytical stress distribution for the elliptical opening fits perfectly the FEA of the U-shaped notch, as can be observed. Consequently, this is the approach followed in the present work.

[Figure 2 about here.]

The SIF solution $\mathcal{K}_{I}(a)$ needed to solve the energy-based criterion corresponds to a central notch that is extended by two cracks of finite dimension, which can be reasonably approximated by a plate with a central crack. For an isotropic plate, $\mathcal{K}_{I}(a)$ is given as:

$$
\mathcal{K}_{I}(a)=Y \sigma^{\infty} \sqrt{\pi a}
$$

where $Y$ is the FWC factor. Several FWC factors exist in the literature. In this work, the simple FWC factor proposed by Chen et al. [9] is used. This FWC factor was derived from a force balance between the remotely applied stress and the internal stress in the elastic material in front of the crack tip, and it is given as:

$$
Y=\frac{1}{\sqrt{1-\left(\frac{2 a}{W}\right)^{2}}}
$$


Note that, by including finite-width corrected solutions for the stress distribution and for the SIF and by approximating the central notch by an elliptical opening instead of a crack, the overall accuracy of the FFMs predictions increase 1-3\%, without noticeable increase in computational effort (these are all closed-form solutions); although it may seem to be a very small improvement, notice that the relative errors of the FFMs predictions are typically below $10 \%$ (see, for example, $[3,6]$ ), which means that this is, in fact, a good improvement. Also, the introduction of these modifications in the FFMs model formulation initially proposed in [3] relaxes some of the restrictions regarding the in-plane dimensions and the aspect ratio of the central notch of the specimens used to quantify the fracture toughness. Therefore, the differences in the FFMs predictions obtained with the solution proposed in the present paper to calculate the fracture toughness or with the solution shown in [3] could be noticeably higher if using center-notched specimens with lower width to notch length ratios $(W /(2 a))$ and/or notches obtained with larger milling cutters (and therefore lower aspect ratios).

\section{Notched strength predictions}

The material investigated by Arteiro et al. [1], and whose notched response in further analysed in this work, is Chomarat's carbon thin-ply NCF C-PLY ${ }^{\mathrm{TM}}$ T700 combined with the AR-2527 epoxy system from Aldila. Two balanced thin-ply laminates, having a nominal ply thickness of $0.08 \mathrm{~mm}$, are investigated: lay-up 1, a $[(0 /-45) /(90 / 45)]_{6 \mathrm{~T}}$ asymmetric laminate, and lay-up 2, a $[(0 /-45) /(45 / 0) /(90 / 45) /(-45 / 90)]_{\mathrm{S}}$ laminate, both manufactured at VX Aerospace using vacuum bagging.

The test results obtained in [1] for the open-hole tension specimens with a $6 \mathrm{~mm}$ diameter hole and for the open-hole compression specimens with a $5 \mathrm{~mm}$ diameter hole were used to calibrate the PS and AS models and calculate the corresponding characteristic distances $\left(r_{o t}\right)$. The tensile and compressive fracture toughness required in the FFMs model were calculated using the FFMs analysis, as described in section 2. Table 1 shows the characteristic distances for the PS and AS models (respectively $r_{o t}^{\mathrm{PS}}$ and $r_{o t}^{\mathrm{AS}}$ ), and the laminate fracture toughness $\left(\mathcal{K}_{I c}\right)$ calculated using the FFMs analysis for both thin-ply laminates in tension and compression.

[Table 1 about here.]

Figure 3 and table 2 show the comparisons between the predictions of the PS, AS and FFMs models and the open-hole tests results obtained using the NCF thin-ply laminates. Table 2 also 
shows the relative errors $\left(\epsilon_{r}\right)$ of the predictions for each tested geometry. It can be observed that all models reasonably predict the notched strength of the NCF thin-ply laminates loaded in both tension and compression.

[Figure 3 about here.]

[Table 2 about here.]

Nevertheless, according to the predictions presented in this work and to discussions presented elsewhere $[3,6,7]$, it can be concluded that the FFMs model shows higher versatility and generality than the alternative PS and AS models, making it better suited to evaluate macroscopic size effects on CFRPs. Because it combines a stress-based criterion with an energy-based criterion, without requiring an inverse calibration from baseline specimens, the FFMs model enables the direct comparison between the notched response of different CFRP laminates. Only the elastic properties, unnotched strengths and fracture toughness of the CFRP laminates under analysis are required to perform such comparisons.

\section{Finite Fracture Mechanics analysis}

\subsection{Notched response and size effect}

Figure 4 shows the notched responses in tension and compression of the thin-ply laminates studied in this work, obtained using FFMs analysis, in terms of the normalized notched strength, defined as $\bar{\sigma}_{N}=\bar{\sigma}^{\infty} / X^{L}$. In addition, figure 4 shows the FFMs analysis for the alternative $[90 / 45 / 0 /-45]_{3 \mathrm{~S}}$ (laminate 1) and $\left[90_{2} / 0_{2} / 45_{2} /-45_{2} / 90 / 0 / 45 /-45\right]_{\mathrm{S}}$ (laminate 2) T800/M21 CFRP laminates, which have a nominal ply thickness of $0.133 \mathrm{~mm}$; these laminates were previously tested by Erçin et al. [6]. Note that laminate 1, as the thin-ply NCF lay-up 1, has dispersed plies with minimal relative ply orientations between adjacent plies (hereafter referred to as "non-blocked laminates"), whereas laminate 2, as the thin-ply $\mathrm{NCF}$ lay-up 2, maximizes the fiber orientation angle between some adjacent plies and it has some plies with the same fiber orientation "blocked" together (hereafter referred to as "blocked laminates"). The FFMs analyses were computed for a width to hole diameter ratio $W / d=4$. The tensile and compressive unnotched strengths (respectively $X_{T}^{L}$ and $X_{C}^{L}$ ), obtained experimentally by Erçin et al. [6], and the tensile and compressive fracture toughnesses $\left(\mathcal{K}_{I c}^{T}\right.$ and 
$\mathcal{K}_{I c}^{C}$ ) for both T800/M21 CFRP laminates, calculated as described in section 2 using the remote stresses at failure (respectively $\bar{\sigma}_{T}^{\infty}$ and $\bar{\sigma}_{C}^{\infty}$ ) measured in center-notched tests [6], are shown in table 3.

[Table 3 about here.]

[Figure 4 about here.]

The FFMs analysis presented in figure 4(a) for the notched response in tension indicates that the hole size effect is more pronounced in the T800/M21 laminates, when compared with the equivalent NCF thin-ply laminates; as expected, blocked laminates show a superior performance as a result of their higher susceptibility to develop sub-critical damage that blunt the notch, ultimately conducting to laminates that are less sensitive to macroscopic size effects. On the other hand, figure 4(b) shows that, unlike what is observed for the tensile case, the hole size effect in compression is less pronounced for the T800/M21 laminates. When comparing the FFMs analyses shown in figure 4 with the experimental results presented in [1], it can be concluded that the FFMs model is able to establish adequate trends that can be very useful in preliminary studies of size effects in composite materials, without the need to conduct extensive experimental programs or complex FEA.

\subsection{Design charts}

The FFMs model can be effectively used to generate design charts for notched laminates. In such design charts, the predicted normalized notched strength is represented as a function of the $2 R / W$ ratio for different hole sizes. These design charts must also include the predictions obtained for a notch-sensitive material, whose normalized strength is a function of the stress concentration factor $K_{T}\left(\bar{\sigma}_{N}=1 / K_{T}\right)$, and the predictions for a notch-insensitive material, whose normalized strength is a function of the geometry $\left(\bar{\sigma}_{N}=1-2 R / W\right)$ - see refs. [1, 3].

Figures 5 and 6 show, respectively, the design charts of the notched response in tension and compression for the thin-ply laminates studied in this work, and for the $[90 / 45 / 0 /-45]_{3 \mathrm{~S}}$ (laminate 1) and $\left[90_{2} / 0_{2} / 45_{2} /-45_{2} / 90 / 0 / 45 /-45\right]_{\mathrm{S}}$ (laminate 2) T800/M21 CFRP laminates [6]. For a constant $2 R / W$ ratio, the predicted normalized strengths for the different hole sizes that are closer to the notch-insensitive boundary correspond to the less notch sensitive laminate.

[Figure 5 about here.] 
It should be stressed that the design charts presented in figures 5 and 6 can be obtained in a fraction of a minute, without the need of extensive experimental programs to determine calibration factors (or "characteristic distances") for each geometry, making it very useful for preliminary sizing and optimization of composite structures with notches. Note also that calculating these design charts using any of the alternative closed-form models would not be effective, since, to do so, a set of openhole tests would be necessary for inverse identification of the characteristic distances, at least for different $2 R / W$ ratios.

\subsection{Notch sensitivity factor}

The FFMs model can be used to assess the inherent brittleness of different combinations of materials and geometries by means of a dimensionless parameter, designated notch sensitivity factor [3]. This dimensionless parameter is defined as:

$$
\eta_{N}=\frac{2 R}{l}
$$

where $l$ is the crack extension at failure and $R$ is the hole radius [3].

Figure 7 shows the relations between the notch sensitivity factor $\left(\eta_{N}\right)$, calculated using the FFMs model, and the hole size $(2 R)$ for the NCF thin-ply laminates studied in this work, and for the $[90 / 45 / 0 /-45]_{3 \mathrm{~S}}$ (laminate 1$)$ and $\left[90_{2} / 0_{2} / 45_{2} /-45_{2} / 90 / 0 / 45 /-45\right]_{\mathrm{S}}$ (laminate 2) T800/M21 CFRP laminates [6]. For the notched response in tension (figure 7(a)), the thin-ply NCF lay-up 2 is clearly less notch sensitive than the remaining laminates, since its notch sensitivity factor is the lowest. This effect is emphasized for large hole diameters. These results also indicate that, for the notched response in tension, use of thin-ply laminates do not necessarily result in a more brittle (or notch sensitive) material, despite their brittle type of failure mode observed in [1]. For the notched response in compression, figure 7(b) shows that the T800/M21 laminate 2 has a notch sensitivity substantially lower than the other laminates. Therefore, and unlike what was observed for the notched response in tension, these results indicate that using NCF thin-ply laminates may result in a reduced notched response in compression.

[Figure 7 about here.] 


\subsection{Discussion}

The FFMs analysis of the notched response, size effect and notch sensitivity presented before clearly shows that thin-ply laminates have great potential, discarding any evidence of inherent brittleness, despite the brittle type of net-section failure mode exhibited in the experimental program presented in [1]. This is particularly true when subjected to tensile loading; although manufactured by vacuum-bagging (resulting in a nominal fiber volume fraction of approximately $50 \%$ ), the notched response of the NCF thin-ply laminates is slightly superior to that exhibited by alternative aerospace grade T800/M21 laminates, which were manufactured using the autoclave and hot-press techniques (nominal fiber volume fraction of 57\%). In addition, the FFMs analysis showed that changing the stacking sequence, i.e. maximizing the relative ply orientations between adjacent plies and "blocking" plies with the same fiber orientation, results in a decrease of the notch sensitivity of both thin-ply and standard laminates; however, with thin-ply laminates, this is achieved reducing the development of subcritical damage, such as delamination and transverse cracking, to a minimum, and keeping a similar, or even superior, notched response.

When subjected to compressive loading, a different picture applies. In this case, the NCF thin-ply laminates exhibit higher notch sensitivity than the corresponding T800/M21 laminates. As in the tensile case, changing the stacking sequence, i.e. maximizing the relative ply orientations between adjacent plies and "blocking" plies with the same fiber orientation, the notch sensitivity decreases in both thin-ply and T800/M21 laminates; however the latter show the best performance. On the other hand, looking to the unnotched compressive strengths of the NCF thin-ply laminates [1] and comparing with those of the corresponding T800/M21 laminates [6], it is observed that, contrary to the tensile case, they do not differ substantially, despite the lower fiber volume fraction of the NCF thin-ply laminates. Therefore, it seems that the use of thin plies, which results in a brittle failure mode dominated by fiber fracture [1], may have a large positive effect in the unnotched compressive behavior (indicating that the in situ effect plays a role not only in tension, but also in compression, as proposed in [10]), although it may also conduct to higher notch sensitivity. Still, an inherently brittle type of compressive behavior is not expected, since the difference between the notched compressive strengths obtained for the NCF thin-ply laminates [1] and for the corresponding T800/M21 laminates [6] is typically below $10 \%$.

Finally, it is important to note that the previous discussion did not take into account the laminate 


\section{Acknowledgements}

This work was funded by AIRBUS under project 2genComp - second generation Composites. The authors gratefully acknowledge the support provided by AIRBUS.

The authors also acknowledge Chomarat (Ardèche, France), Aldila (Poway, California USA), VX Aerospace (Leesburg, Virginia USA), and Prof. S.W. Tsai (Stanford University, USA) for providing 
the material used in the experimental program carried out in [1], and Dr. Peter Linde (AIRBUS) for the useful discussions. The first, second and third authors would like to acknowledge the support of the Fundação para a Ciência e a Tecnologia under grants SFRH/BD/88593/2012 and FCT-DFRHSFRH-BPD-78104-2011, and program Ciencia2008, respectively. 


\section{References}

[1] Arteiro A, Catalanotti G, Xavier J, Camanho PP. Notched response of non-crimp fabric thin-ply laminates. Compos Sci Technol 2013;79:97-114.

[2] Whitney JM, Nuismer RJ. Stress fracture criteria for laminated composites containing stress concentrations. J Compos Mater 1974;8:253-265.

[3] Camanho PP, Erçin GH, Catalanotti G, Mahdi S, Linde P. A finite fracture mechanics model for the prediction of the open-hole strength of composite laminates. Compos Part A-Appl S 2012;43:1219-1225.

[4] Leguillon D. Strength or toughness? A criterion for crack onset at a notch. Eur J Mech A-Solid 2002;21:61-72.

[5] Cornetti P, Pugno N, Carpinteri A, Taylor D. Finite fracture mechanics: A coupled stress and energy failure criterion. Eng Fract Mech 2006;73:2021-2033.

[6] Erçin GH, Camanho PP, Xavier J, Catalanotti G, Mahdi S, Linde P. Size effects on the tensile and compressive failure of notched composite laminates. Compos Struct 2013;96:736-744.

[7] Maimí P, González EV, Gascons N, Ripoll L. Size effect law and critical distance theories to predict the nominal strength of quasibrittle structures. Appl Mech Rev 2013;65(2):020802020802-16.

[8] Tan SC. Stress Concentrations in Laminated Composites. Lancaster: Technomic, 1994.

[9] Chen DL, Weiss B, Stickler R. A new geometric factor formula for a center cracked plate tensile specimen of finite width. Int J Fracture 1992;55:R3-R8.

[10] Catalanotti G, Camanho PP, Marques AT. Three-dimensional failure criteria for fiber-reinforced laminates. Compos Struct 2013;95:63-79.

[11] Green BG, Wisnom MR, Hallett SR. An experimental investigation into the tensile strength scaling of notched composites. Compos Part A-Appl S 2007;38:867-878. 


\section{List of Figures}

1 Composite laminate with a central notch loaded in tension. . . . . . . . . . . . . . . 15

2 Normalized stress distributions along the $x$-axis in the vicinity of the notch tip. The elliptical openings resemble a $4 \mathrm{~mm}$ long notch, with a notch tip radius of $0.5 \mathrm{~mm}$ and a width to notch length ratio $(W /(2 a))$ equal to 7.5 . Finite-width corrected solutions are considered. . . . . . . . . . . . . . . . . . . . 16

3 Predictions and experimental results. . . . . . . . . . . . . . . . . . 17

4 Finite Fracture Mechanics analysis and notched response of the NCF thin-ply laminates, and comparison with alternative T800/M21 CFRP laminates. . . . . . . . . 18

5 Design charts for the notched response in tension of different CFRP laminates. . . . . 19

6 Design charts for the notched response in compression of different CFRP laminates. . 20

7 Notch sensitivity factor as a function of the hole size for the NCF thin-ply laminates, and for the alternative $[90 / 45 / 0 /-45]_{3 \mathrm{~S}}$ (laminate 1 ) and $\left[90_{2} / 0_{2} / 45_{2} /-\right.$ $45_{2} / 90 / 0 / 45 /$ - 45] $]_{\mathrm{S}}$ (laminate 2) T800/M21 CFRP laminates. . . . . . . . . . . . 21 


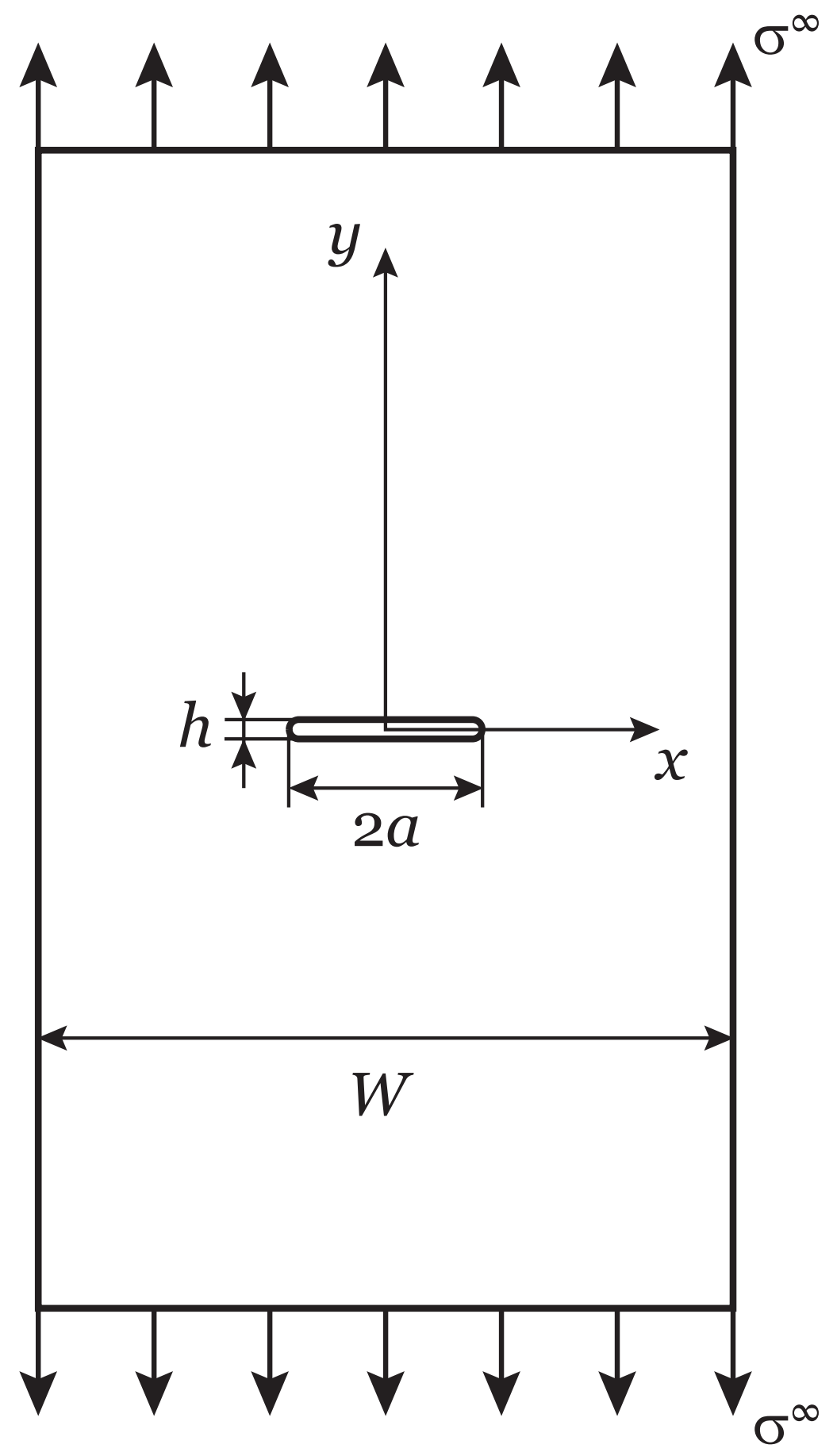

Figure 1: Composite laminate with a central notch loaded in tension. 


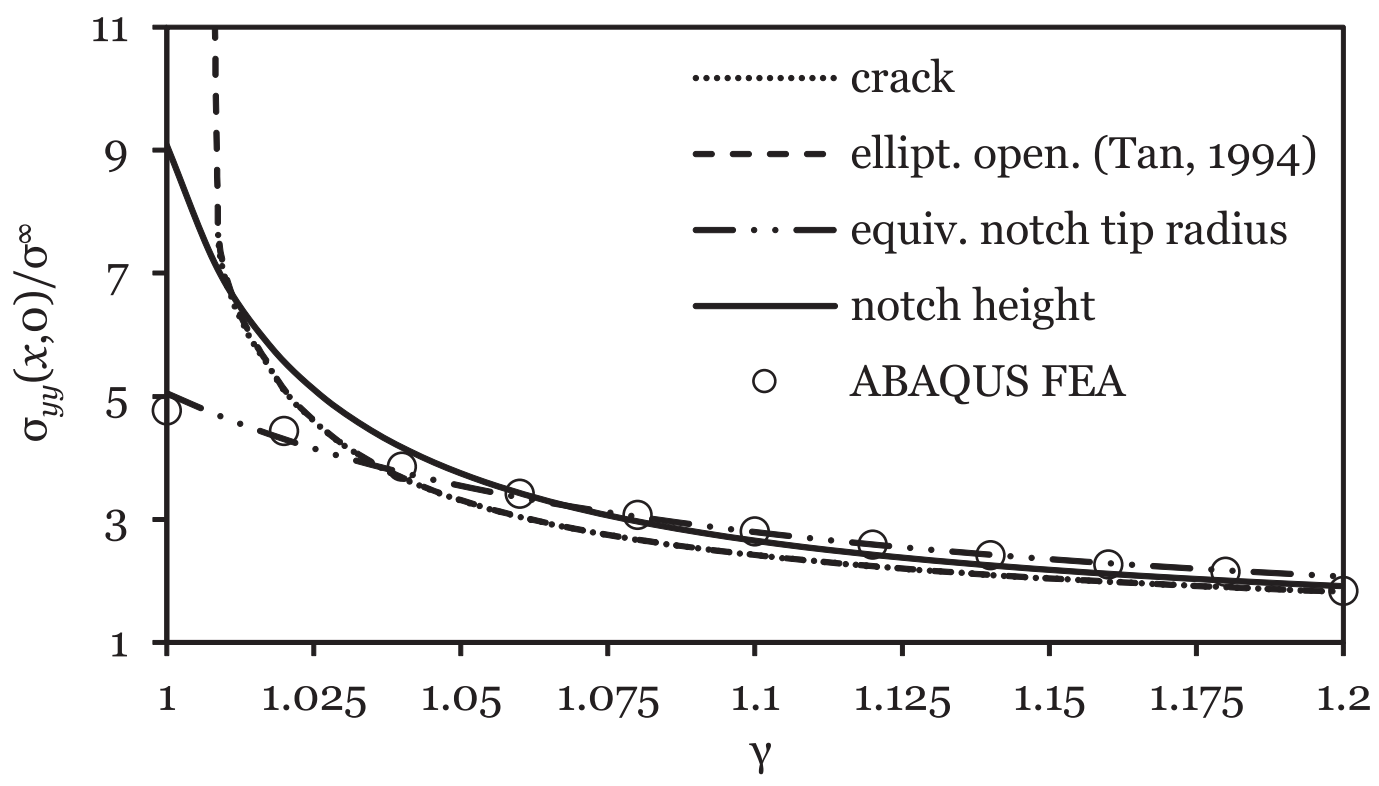

Figure 2: Normalized stress distributions along the $x$-axis in the vicinity of the notch tip. The elliptical openings resemble a $4 \mathrm{~mm}$ long notch, with a notch tip radius of $0.5 \mathrm{~mm}$ and a width to notch length ratio $(W /(2 a))$ equal to 7.5. Finite-width corrected solutions are considered. 


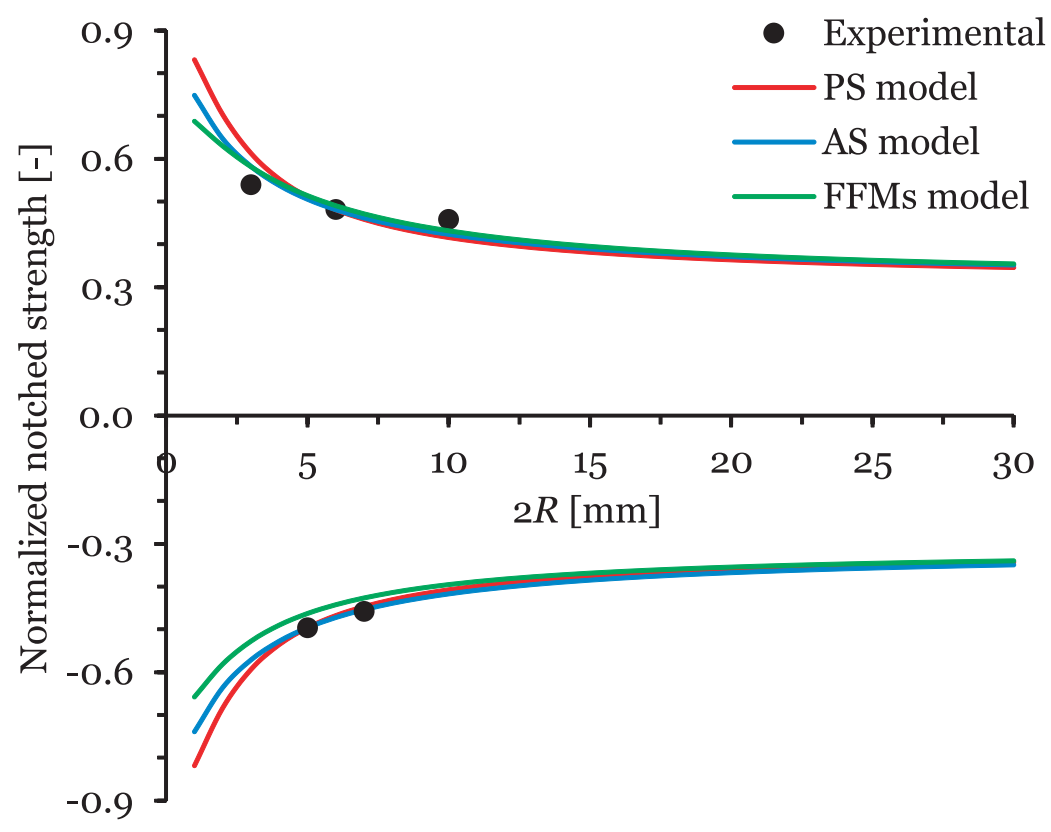

(a) Open-hole lay-up 1 specimens.

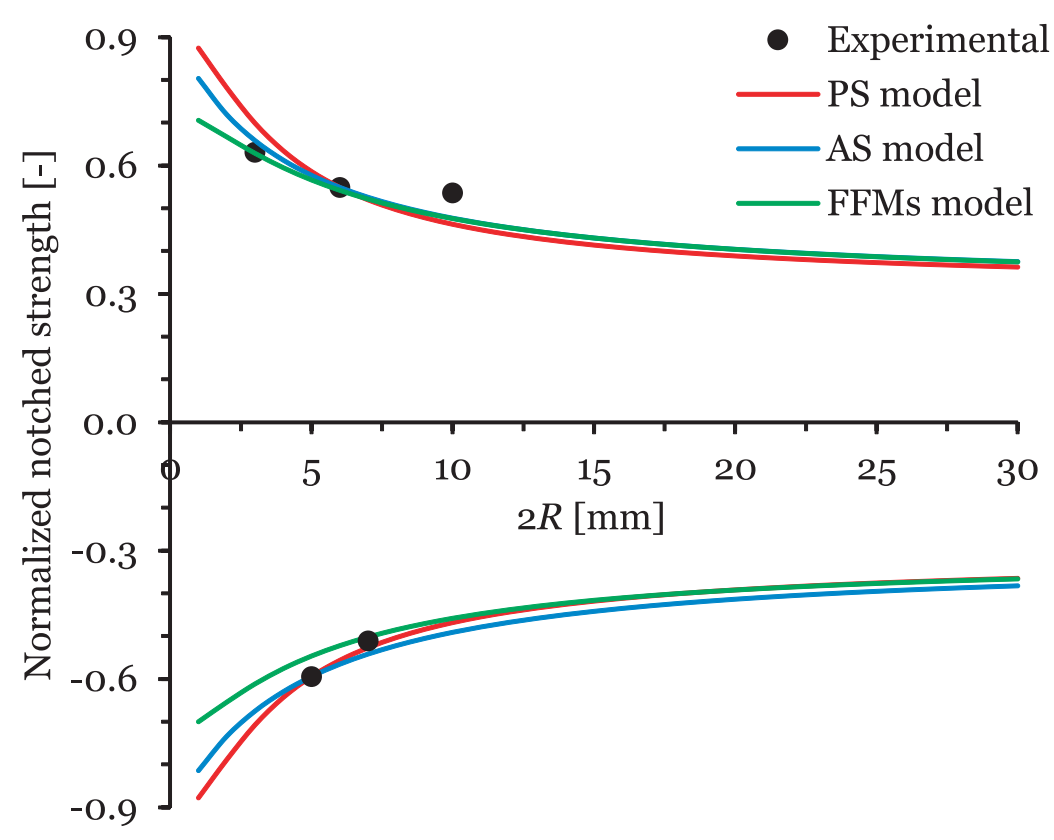

(b) Open-hole lay-up 2 specimens.

Figure 3: Predictions and experimental results. 


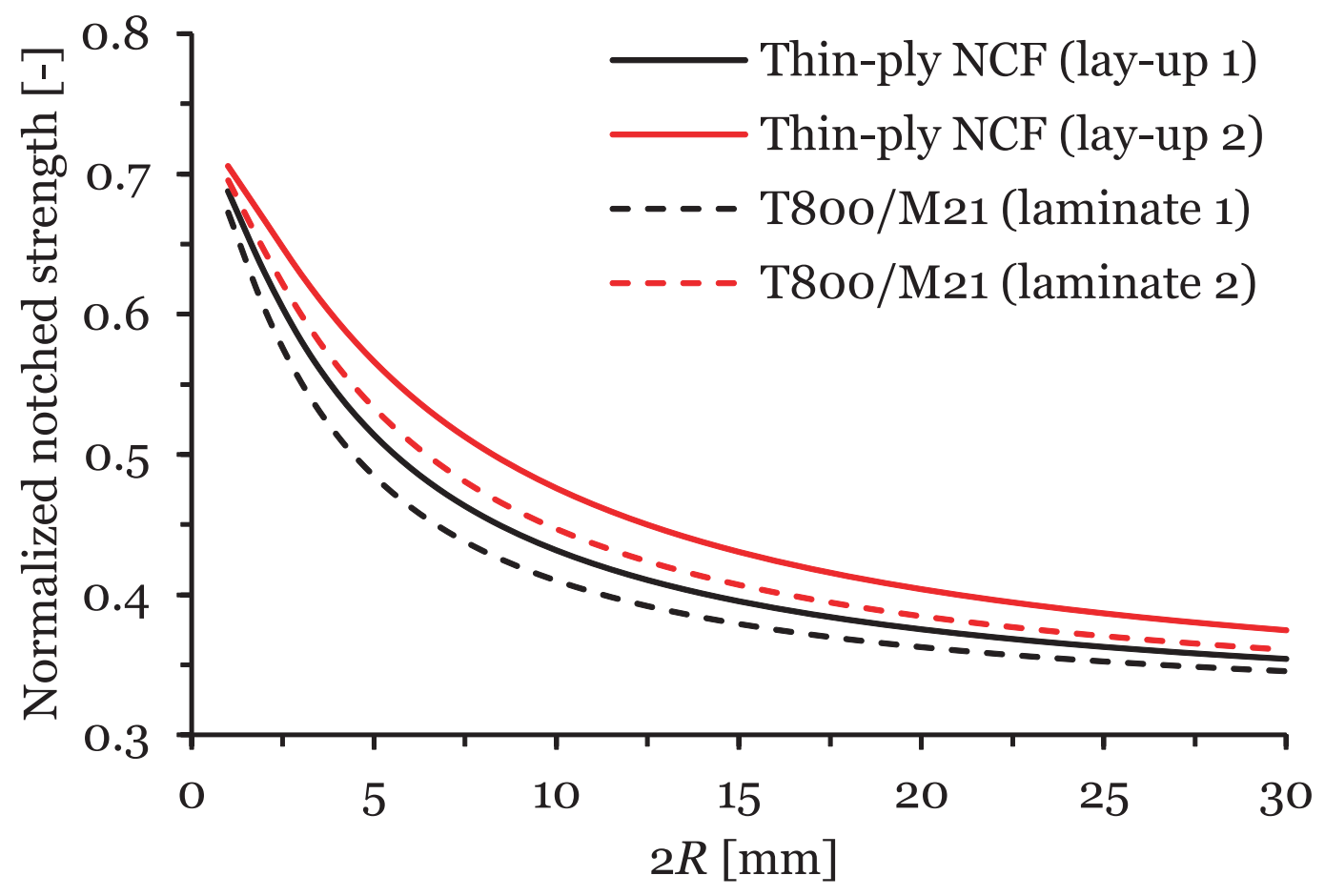

(a) Tension.

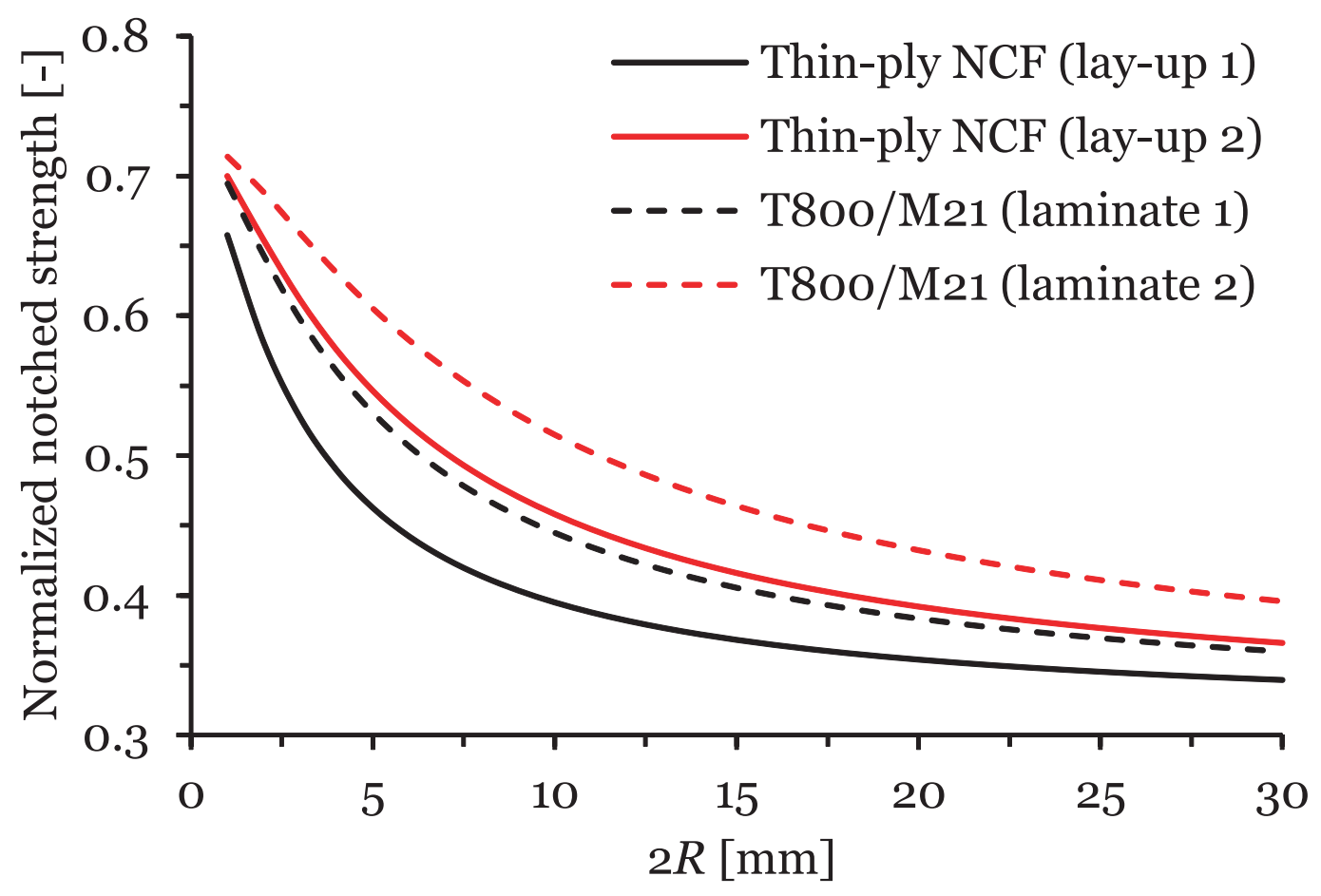

(b) Compression.

Figure 4: Finite Fracture Mechanics analysis and notched response of the NCF thin-ply laminates, and comparison with alternative T800/M21 CFRP laminates. 


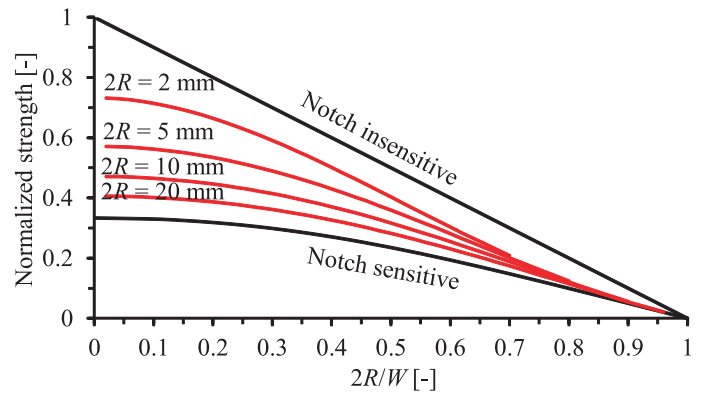

(a) Thin-ply NCF (lay-up 1).

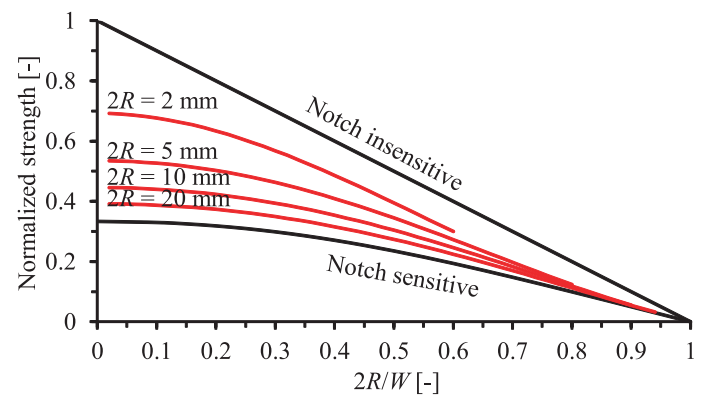

(c) T800/M21 (laminate 1).

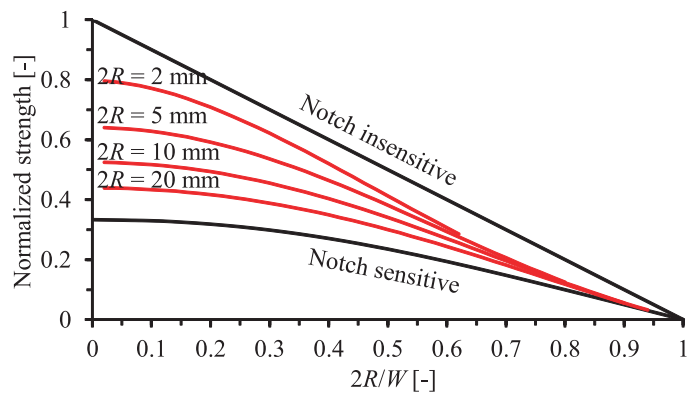

(b) Thin-ply NCF (lay-up 2).

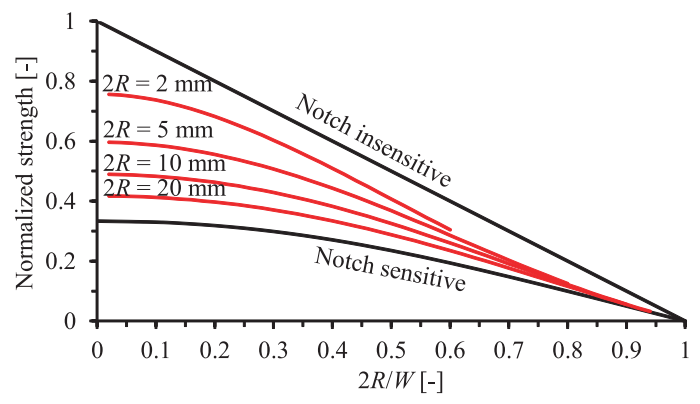

(d) T800/M21 (laminate 2).

Figure 5: Design charts for the notched response in tension of different CFRP laminates. 


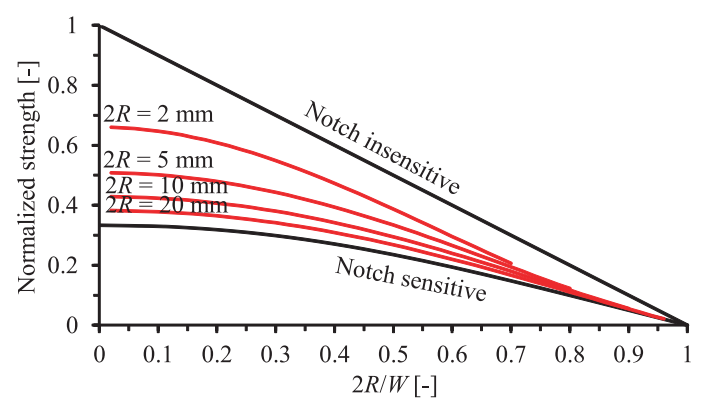

(a) Thin-ply NCF (lay-up 1).

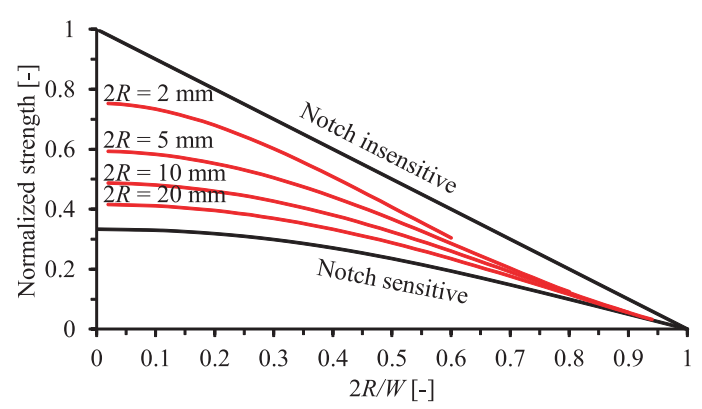

(c) T800/M21 (laminate 1).

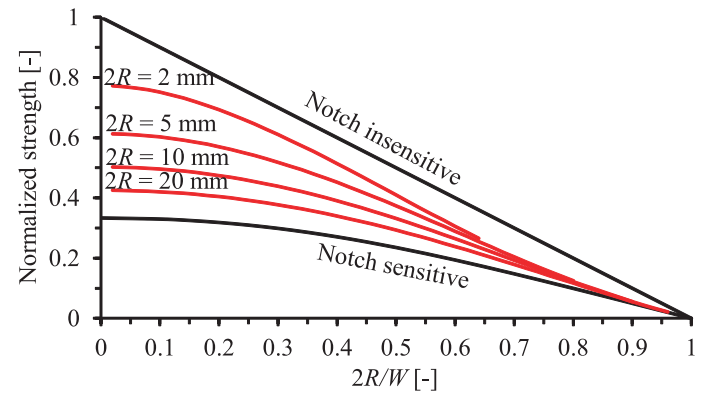

(b) Thin-ply NCF (lay-up 2).

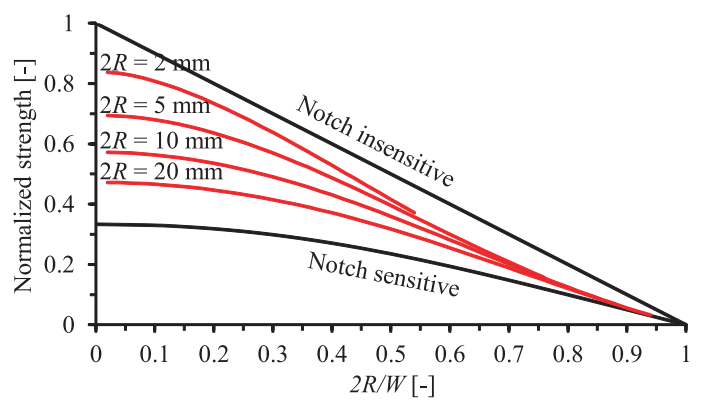

(d) T800/M21 (laminate 2).

Figure 6: Design charts for the notched response in compression of different CFRP laminates. 


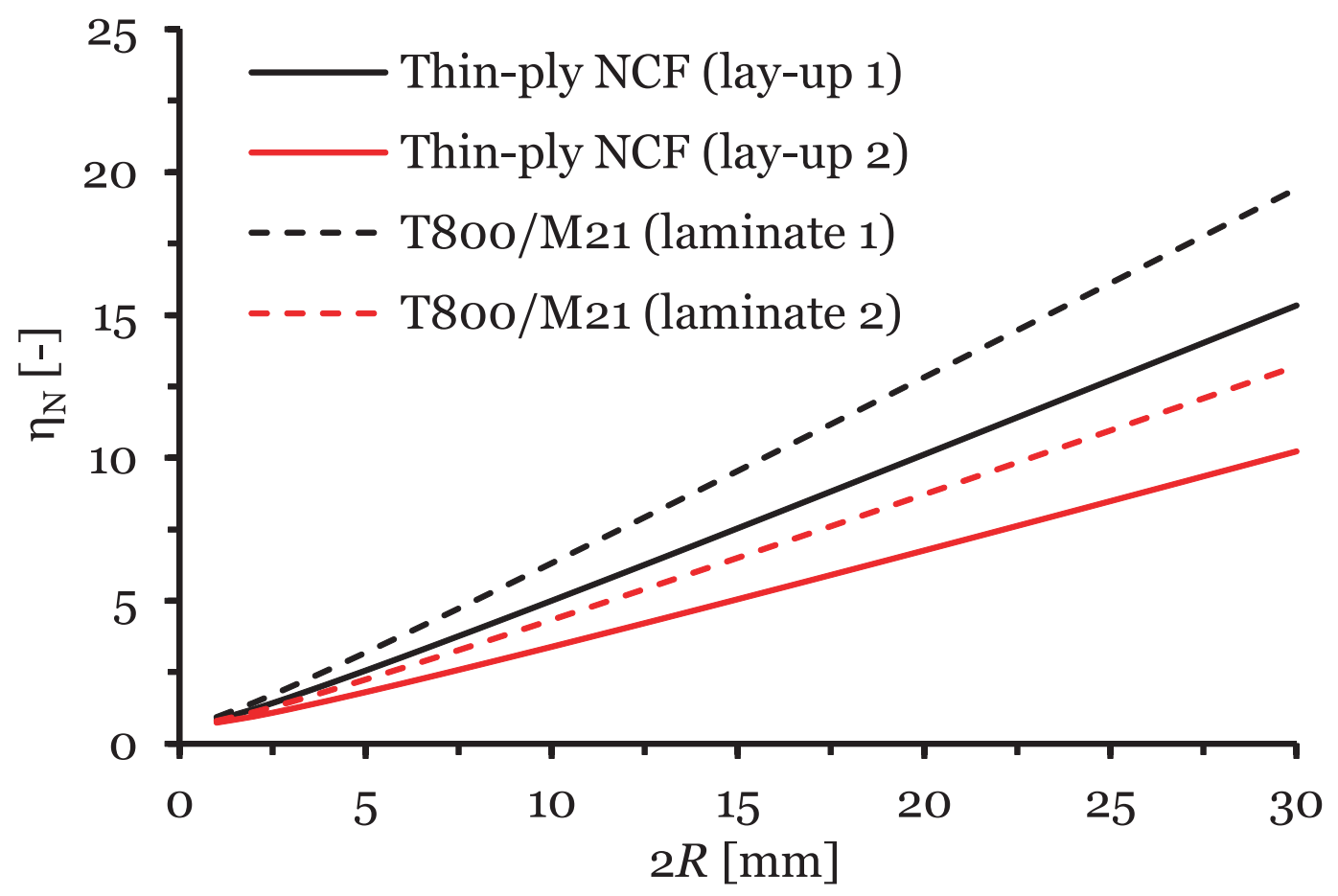

(a) Notched response in tension.

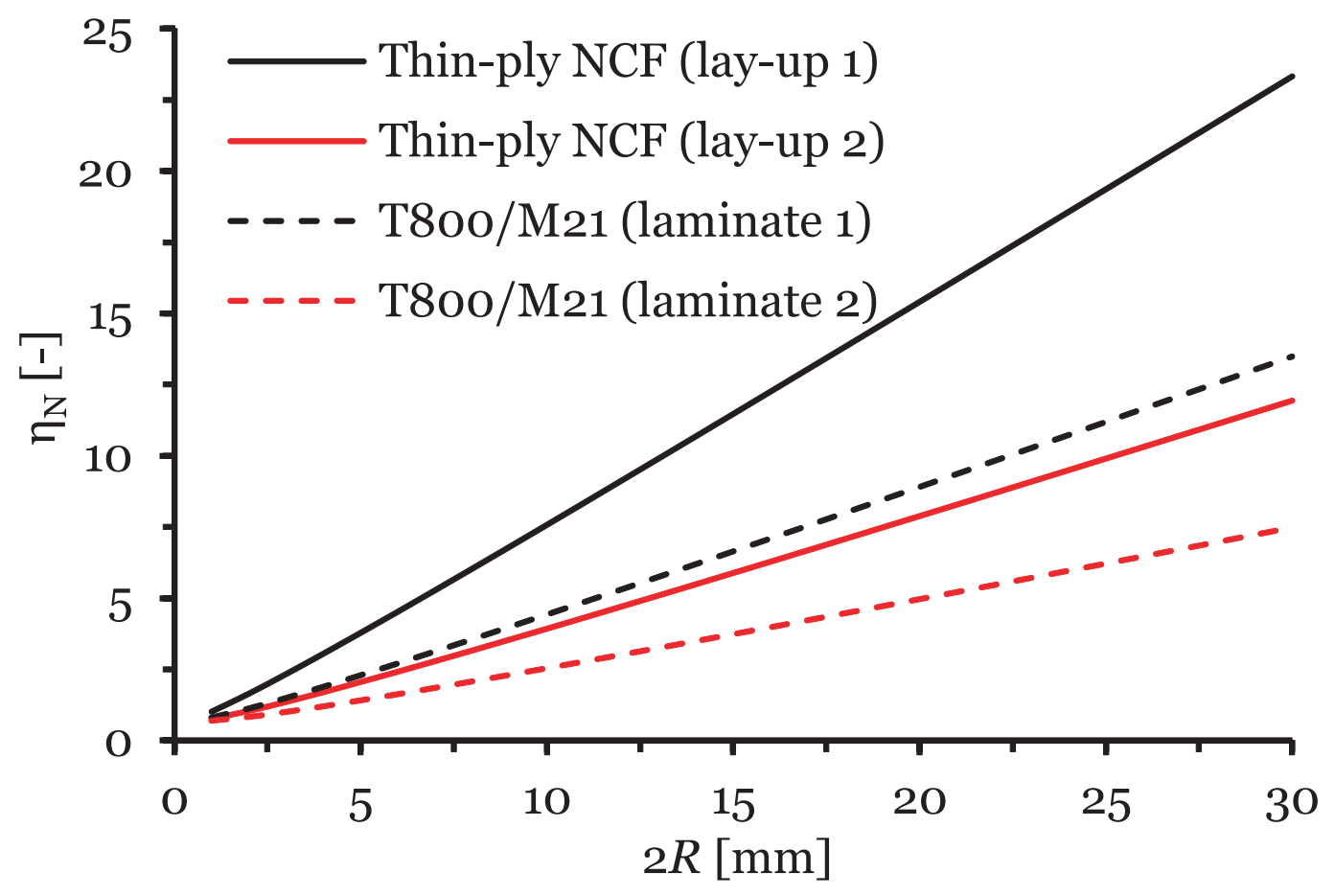

(b) Notched response in compression.

Figure 7: Notch sensitivity factor as a function of the hole size for the NCF thin-ply laminates, and for the alternative $[90 / 45 / 0 /-45]_{3 \mathrm{~S}}$ (laminate 1 ) and $\left[90_{2} / 0_{2} / 45_{2} /-45_{2} / 90 / 0 / 45 /-45\right]_{\mathrm{S}}$ (laminate 2) T800/M21 CFRP laminates. 


\section{List of Tables}

1 Characteristic distances and laminate fracture toughnesses required to predict the notched response of the NCF thin-ply laminates. . . . . . . . . . . . . . . . . 23

2 Predictions and relative errors. . . . . . . . . . . . . . . . . . . . . 24

3 Tensile and compressive unnotched strengths and predicted tensile and compressive fracture toughnesses for the $[90 / 45 / 0 /-45]_{3 \mathrm{~S}}$ (laminate 1 ) and $\left[90_{2} / 0_{2} / 45_{2} /-45_{2} / 90 / 0 / 45 /-\right.$ $45]_{\mathrm{S}}$ (laminate 2) T800/M21 CFRP laminates. . . . . . . . . . . . . . . 25 
Table 1: Characteristic distances and laminate fracture toughnesses required to predict the notched response of the NCF thin-ply laminates.

\begin{tabular}{llrrr}
\hline Laminate & Load type & $r_{o t}^{\mathrm{PS}}(\mathrm{mm})$ & $r_{o t}^{\mathrm{AS}}(\mathrm{mm})$ & $\mathcal{K}_{I c}(\mathrm{MPa} \sqrt{\mathrm{m}})$ \\
\hline Lay-up 1 & Tension & 0.75 & 1.84 & 49.1 \\
& Compression & 0.69 & 1.71 & 27.0 \\
Lay-up 2 & Tension & 1.11 & 2.97 & 53.1 \\
& Compression & 1.15 & 3.30 & 32.2 \\
\hline
\end{tabular}


Table 2: Predictions and relative errors.

\begin{tabular}{cccccccr}
\hline \multicolumn{3}{c}{ PS model } & \multicolumn{3}{c}{ AS model } & \multicolumn{3}{c}{ FFMs model } \\
$2 R(\mathrm{~mm})$ & $\bar{\sigma}_{T}^{\infty}(\mathrm{MPa})$ & $\epsilon_{r}(\%)$ & $\bar{\sigma}_{T}^{\infty}(\mathrm{MPa})$ & $\epsilon_{r}(\%)$ & $\bar{\sigma}_{T}^{\infty}(\mathrm{MPa})$ & $\epsilon_{r}(\%)$ \\
\hline Open-hole lay-up 1 specimens loaded in tension \\
3 & 490 & 13.6 & 466 & 7.9 & 465 & 7.8 \\
6 & 385 & $\mathrm{n} / \mathrm{a}$ & 385 & $\mathrm{n} / \mathrm{a}$ & 392 & 1.9 \\
10 & 333 & -9.2 & 339 & -7.6 & 345 & -5.8 \\
Open-hole lay-up 2 specimens loaded in tension \\
3
\end{tabular}


Table 3: Tensile and compressive unnotched strengths and predicted tensile and compressive fracture toughnesses for the $[90 / 45 / 0 /-45]_{3 \mathrm{~S}}$ (laminate 1 ) and $\left[90_{2} / 0_{2} / 45_{2} /-45_{2} / 90 / 0 / 45 /-45\right]_{\mathrm{S}}$ (laminate 2) T800/M21 CFRP laminates.

\begin{tabular}{lrrrr}
\hline Laminate & $X_{T}^{L}(\mathrm{MPa})$ & $X_{C}^{L}(\mathrm{MPa})$ & $\mathcal{K}_{I c}^{T}(\mathrm{MPa} \sqrt{\mathrm{m}})$ & $\mathcal{K}_{I c}^{C}(\mathrm{MPa} \sqrt{\mathrm{m}})$ \\
\hline Laminate 1 & 1053 & 539 & 57.6 & 35.2 \\
Laminate 2 & 973 & 503 & 64.2 & 43.8 \\
\hline
\end{tabular}

